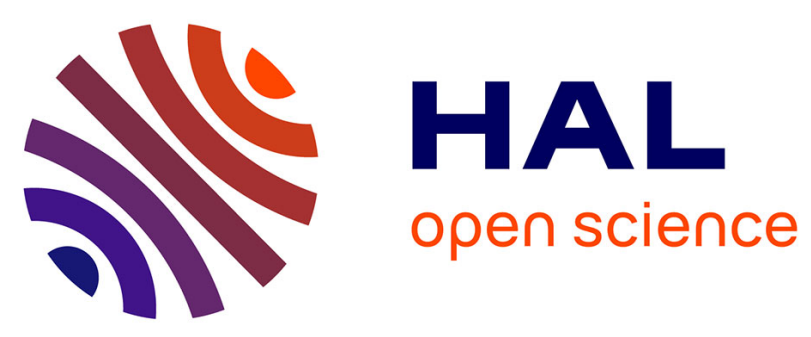

\title{
A new experimental set-up for the study of the formation and dissociation of methane hydrate in sediments
}

Olivier Bonnefoy, Jean-Michel Herri, Jean-Pierre Monfort, Pierre Henry, Philippe Bernada, Roy Ohmura

\section{To cite this version:}

Olivier Bonnefoy, Jean-Michel Herri, Jean-Pierre Monfort, Pierre Henry, Philippe Bernada, et al.. A new experimental set-up for the study of the formation and dissociation of methane hydrate in sediments. EAGE 63rd Conference and Exhibition, Jun 2001, Amsterdam, Netherlands. hal-00846009

\section{HAL Id: hal-00846009 https://hal.science/hal-00846009}

Submitted on 18 Jul 2013

HAL is a multi-disciplinary open access archive for the deposit and dissemination of scientific research documents, whether they are published or not. The documents may come from teaching and research institutions in France or abroad, or from public or private research centers.
L'archive ouverte pluridisciplinaire HAL, est destinée au dépôt et à la diffusion de documents scientifiques de niveau recherche, publiés ou non, émanant des établissements d'enseignement et de recherche français ou étrangers, des laboratoires publics ou privés. 


\title{
A new experimental set-up for the study of the Formation and Dissociation of Methane Hydrate in Sédiments
}

\author{
AUTHOR \\ O. BONNEFOY ${ }^{1}$, J.-M. HERRI ${ }^{1}$, J.P. MONFORT ${ }^{2}$, P. HENRY ${ }^{3}$, P. BERNADA ${ }^{4}$, R. OHMURA ${ }^{2,5}$ \\ Address \\ ${ }^{1}$ Ecole Nationale Supérieure des Mines de Saint-Etienne, Centre SPIN, 158 Cours Fauriel \\ 42023 Saint-Etienne Cedex, FRANCE \\ ${ }^{2}$ ENSIACET and Laboratoire De Génie Chimique de Toulouse, FRANCE \\ ${ }^{3}$ Ecole Normale Supérieure and Laboratoire de Géologie, FRANCE \\ ${ }^{4}$ Ecole Nationale Supérieure d'Ingénieur en Génie des Technologies Industrielles (ENSGTI) and \\ Laboratoire de Génie des Procédés de Pau, FRANCE \\ ${ }^{5}$ Dept. Mech. Eng. Keio University, JAPAN
}

This work is sponsored by TotalFinaElf, IFREMER, IFP, GDF and CNRS

\begin{abstract}
In this paper, we give a short presentation of the project ForDiMHyS which consists of experimental studies and model establishment (or development) of the kinetics of FORmation and Dissociation of Methane Hydrates in Sediments. We focus on the details of the experimental set-up which is newly, specially designed for this study in the preliminary step of the project.

The four French academic teams and two Ph.D. theses are involved in the ForDiMHyS project on the period 2000-2004. The financial support is given by the five French Partners. The project consists of two-step programs; firstly the data acquisition from the laboratory experimental set-up and secondly simulation of methane production from methane hydrate fields.
\end{abstract}

\section{Context}

It is currently accepted that huge quantity of methane is stored in the form of methane hydrate in the continental sediments under permafrost, or in the deep-sea sediments. In the arctic area, some exploratory drillings coupled with the seismic analyses have leaded to validating the estimation of the resources of an amount of $3.10^{13} \mathrm{~m}^{3}$ STP methane gas. In the deep-sea conditions, the current estimation gives a resource of $20.10^{15} \mathrm{~m}^{3}$ STP which is subjected to discussion and could over-evaluate the reality by a factor of 20 or 100 .

Whatever the exact quantity, the amount of methane which is stored in methane hydrate crystals is sufficiently large to overcome different doubts concerning the possibility to consider methane hydrate as a resource of gas, or to question us on geo-hazard events linked to the petroleum drilling or to the global climate change. Such questions are :

Resources: characterisation of potential methane resources entrapped in hydrates-related sediments and technological challenges of an economical production of methane from these deposits.

Industrial and geohazard : as conventional hydrocarbon production moves into deeper water, gas hydrates become an increasing drilling and production hazard. Engineering activities in the regions where in situ hydrates occur must deal with the consequences of gas hydrate dissociation. 
Also, at a larger scale, naturally occurring hydrate dissociation can contribute to the instability of some continental margins which could result in the deep-sea landslides.

Climate change : recent concern with the green house effect has emphasised the need to understand the role of methane and its hydrates deposits in global carbon cycles.

All these questions require to understand the dynamics of the hydrate fields after a modification of their thermodynamic conditions, which implies simulating the behaviour of a global hydrate field. In such a simulation, some intrinsic properties of a hydrated sediment are indispensable whereas they are not known currently.

The goal of the ForDiMHyS project consists in measuring some of the unknown properties in order to propose a model of a gas production from methane hydrate in sediments.

\section{Experimental set-up}

The programme is so designed as to obtain the experimental data on hydrate formation /dissociation under in situ temperature and pressure conditions of methane hydrate in distinct porous materials. It is also expected, as a future target, to compare the laboratory data with marine drilling and sampling data that have been collected from the seabed (data from ODP and oceanographic cruises).

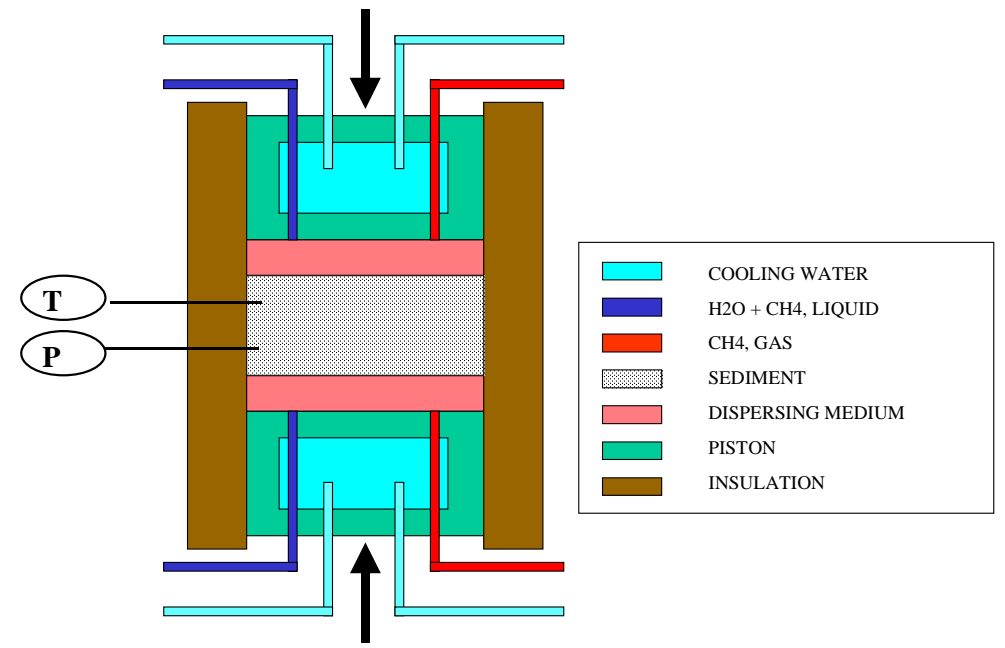

Figure 1

Schematic of the main reactor

A newly designed high-pressure vessel (figure 1 and 2) is now under actual construction in the laboratory of Ecole des Mines de Saint-Etienne. The vessel can contain a cylindrical reduced-size sediment specimen of around $10 \mathrm{~cm}$ diameter and $5 \mathrm{~cm}$ height.

The hydrostatic and burial pressures could be imposed respectively in the ranges [0-200 bars] and [0-250 bars]. The burial pressure is obtained by the way of a moving piston which presses the lower face of the sample.

The temperatures of the upper and the lower faces can be controlled each independently in the range $\left[-20,+20^{\circ} \mathrm{C}\right]$ so that a temperature gradient could be imposed in order to measure the thermal conductivity of the sample. 


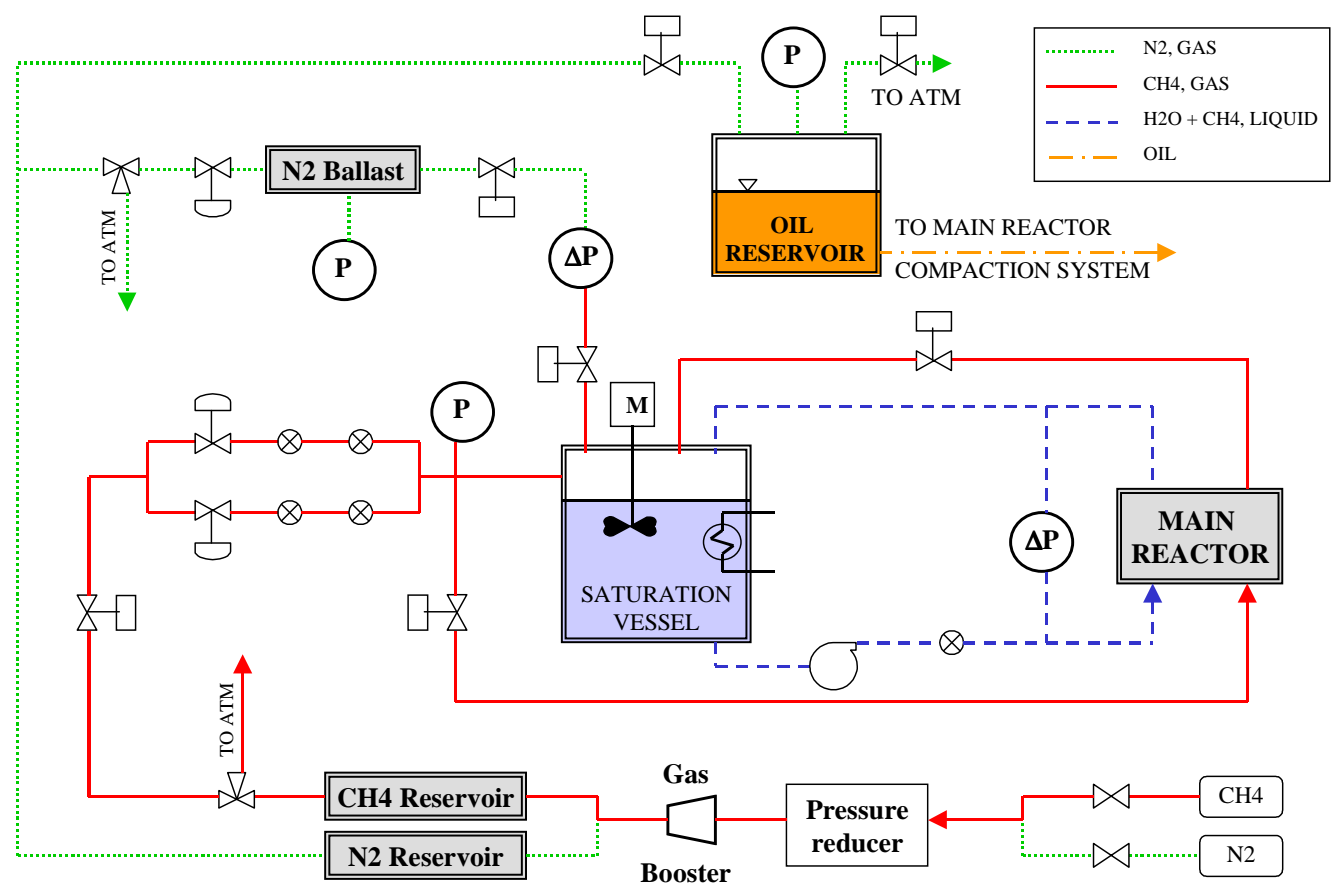

Figure 2

Schematic of the equipment

The hydrostatic pressure is maintained at a constant level by the way of two methods, each of them allowing us to measure the amount of the methane that has been consumed or released in or from the sample during formation and dissociation of hydrate crystals.

- Firstly, the sample is directly connected gas socket instrumented with a mass flow controller that could inject or release methane gas in order to maintain the pressure at a constant level during hydrate formation or dissociation. This method has been applied successfully on a previous reactor devoted to the determination of gas hydrate crystallisation in pure water [1]. It allows us to measure continuously the amount of methane in the sample and to control the kinetic of gas consumption during formation or dissociation. By this way, we can directly measure the kinetic behaviour of the sediment which is subjected to a stepwise pressure depletion or temperature increase.

- Secondly, the sample is connected to an external reactor containing pure water at constant temperature and methane gas at constant pressure. So that, the reactor acts as a reservoir of water with controlled methane concentration (solubility) depending on the pressure and temperature conditions. During experimental runs, a water loop circulation could be imposed continuously between the external reactor and the sample reactor, which allows us:

- to measure continuously the amount of the methane that has been reacting with the hydrate particles contained in the sediment during the crossing of it.

- More over, the water flow rate is monitored and pressure drop of water crossing the sample in measured in a way to back calculate the permeability of sediment and to compare it to the amount of hydrate phase in the sediment.

In the near future, other properties such as elastic properties of the hydrated sediments, electrical resistivity in the course of hydrate/formation/dissociation in the porous sample will be also investigated.

So, this equipment is devoted to the measurement of various physical parameters

- amount of hydrate crystal in the sediment,

- kinetic of crystallisation or dissociation, 
- thermal conductivity,

- permeability,

- wave speed celerity.

\section{Experimental program}

The objectives of the experimental program is to retrieve experimental data which are necessary to simulate the dynamic behaviour of an hydrate field which is subjected to a sudden (or abrupt) modification of its thermodynamic conditions : decrease of the pressure and/or increase of the temperature.

So different parameters will be investigated

- effect of sediment type, burial depth and temperature,

- effect of methane saturated water fluxes on the kinetic rates,

- characterisation of methane recovered by thermal and depressurisation stimulation on sediment specimens,

- change of the permeability during the hydrate crystal growth or thawing,

- change of the thermal conductivity,

- change of the acoustic and resistivity properties

The experimental set-up design and program is performed as a $\mathrm{Ph} . \mathrm{D}$ work at ENS des Mines de Saint-Etienne on the period 2000-2003

\section{Modelling program}

The program involves a second step which is the modelling of gas production from a hydrate field. The objective of this second phase is to simulate the heat and mass transfer in a porous media containing methane hydrates susceptible to grow or to thaw.

The simulation would allow us to understand the kinetic behaviour during gas production at different scales, from the laboratory scale to the hydrate field scale.

Two different approaches will be considered.

- The first approach consists in re-building a new porous solid model from an academic view which takes into account the hydrate phase at the beginning. This approach will be performed as a Ph.D work at the ENSGTI on the period 2001-2004. It will focus on the modelling of the up-scaling from the laboratory to a mid-size of some cubic meters.

- The second approach consists in re-using a commercial software of gas production (SARIP from IFP) and modify it in order to introduce the appearance of the hydrate phase which is not taken into account usually. This approach will focus on the modelling from the mid-size to the gas field scale.

\section{Reference}

[1] Herri (J.-M.), GRUY (F.), PIC (J.-S.), COURnil (M.), CingotTi (B.) ET SinQUiN (A.) Interest of in situ particle size determination for the characterization of methane hydrate formation. Application to the study of kinetic inhibitors. Chemical Engineering Science, Vol. 54, No. 12, pp. 1849-1858, 1999 